Article

\title{
Challenges with Measuring Learning through Digital Gameplay in K-12 Classrooms
}

\author{
Cristyne Hébert ${ }^{1, *}$, Jennifer Jenson ${ }^{1}$ and Katrina Fong ${ }^{2}$ \\ ${ }^{1}$ Faculty of Education, York University, Toronto, M3J 1P3, Canada; E-Mails: cristyne_hebert@edu.yorku.ca (C.H.), \\ jjenson@edu.yorku.ca (J.J.) \\ 2 Department of Psychology, York University, Toronto, M3J 1P3, Canada; E-Mail: kafong@yorku.ca \\ * Corresponding author
}

Submitted: 15 January 2018 | Accepted: 6 April 2018 | Published: 7 June 2018

\begin{abstract}
Videogames have long been lauded for their potential to increase engagement and enhance learning when used in classrooms. At the same time, how to best evaluate learning presents challenges, especially when the game does not have standardized assessments built-into it and when games are taken up in a wide variety of ways in quite diverse contexts. This article details the use of a geography game to support learning in 32 diverse classrooms in Ontario, Canada, alongside challenges with evaluating student learning using a game that did not have a built-in assessment system. In total, 795 students participated in the study. Classroom observations and interviews with teachers were triangulated with student pre and post evaluations. Results demonstrated that students did learn from gameplay, as demonstrated through multiple choice and short answer change scores in the pre to post evaluation, despite variations in duration of play and how the game was integrated in the classroom more generally.
\end{abstract}

\section{Keywords}

assessment; digital games; game-based learning; games

\section{Issue}

This article is part of the issue "Games Matter? Current Theories and Studies on Digital Games", edited by Julia Kneer and Ruud Jacobs (Erasmus University Rotterdam, The Netherlands).

(C) 2018 by the authors; licensee Cogitatio (Lisbon, Portugal). This article is licensed under a Creative Commons Attribution 4.0 International License (CC BY).

\section{Introduction}

Proponents of digital games have argued that they can be effective tools for supporting student learning in K-12 classroom spaces, creating playful and immersive environments that are more engaging than traditional methods of instruction (Gee, 2005; Prensky, 2006; Shaffer, Squire, Halverson, \& Gee, 2005; Squire \& Jenkins, 2003). The benefits of using games to support subject-specific learning have been well-documented (Kirriemuir \& Mcfarlane, 2007; Mitchell \& Savill-Smith, 2004). For geography learning in particular, digital games can support understanding of geographical space, as players move through 2D and 3D environments and experience them from various vantage points (da Silva, 2015). Representations of place and space can also be explored through digital envi- ronments, that are more explicitly constructed than real world spaces and can allow for comparative analyses of digital worlds and physical locations outside of game spaces (Dittmer, 2010). And some digital games, such as Where in the World is Carmen Sandiago, Treasures of Knowledge, Quest Atlantis and GeoNet do, to varying degrees, support alignment with elements of the social studies curriculum - the area of the curriculum where in many places, including Ontario, geography is studied up to grade six (Brysch, Huynh, \& Scholz, 2012). Yet, as the incorporation of digital games into K-12 curricula is relatively new, more evidence on their use as a means of supporting students' learning, specifically, is needed (Annetta, 2008; Linderoth, 2012; Young et al., 2012).

Research on using games in $\mathrm{K}-12$ classrooms to support student geography learning is sparse. Virvou, Kat- 
sionis and Manos (2005) conducted a multi-part study evaluating student learning with the digital geography game VR-ENGAGE, dividing students into groups according to their academic performance. Focusing on the number of questions students answered incorrectly, or their "mistakes" between pre and post test, they found that scores increased to a greater degree in students with typically lower academic performance. Their findings indicate that the use of digital games in classroom contexts may be particularly beneficial for lower performing, and less engaged students.

Other research has studied games that cover multiple subject areas including geography, rather than targeting geographic learning exclusively. Cheung et al. (2008) conducted a small exploratory study with high school students playing Farmtasia-a simulation game about complex farming systems. Analysis of pre and post test scores indicated that students scored higher on the post test, demonstrating that students learned through gameplay. Buch and Egenfeldt-Nielsen (2007) examined the game Global Conflicts: Palestine with high school students during a four-day game course. Their exploration focused mainly on student perceptions of the game, with the "learning experience" evaluated by asking students if they learned more, as much, less than or nothing in comparison with learning through "normal" (i.e., not game-focused) courses. They found that higher numbers of students reported that they learned more through the game course than those who learned as much or less than the normal course or learned nothing at all. Dourda, Bratitsis, Griva and Papadopoulou (2014) used Whodunit, a detective game centered on global landmarks, as a means of developing English language and geography vocabulary with English as a foreign language students. Student learning was evaluated using pre and post "knowledge tests", that consisted of true and false and multiple choice fact-based questions (e.g., "which river runs through the Grand Canyon"; p. 250). Findings demonstrated that student scores increased from pre to post test, showing that students were enhancing their vocabulary, alongside their geographic understanding, through gameplay. Finally, Tüzün, Yilmaz-Soylu, Karakuş, Inal and Kizilkaya (2009) assessed the learning of 13 elementary school students using Quest Atlantis. Results from pre and post tests demonstrated learning, as students' scores increased.

How to appropriately and adequately assess learning through games in educational contexts has also been the subject of much debate. First, the overreliance on standardized, pencil and paper, pre and post assessments as the sole means of evaluating learning has been called into question (Jenson, de Castell, Thumlert, \& Muehrer, 2016; Rowan \& Beavis, 2017). These modes of assessment fail to capture the multimodal competencies developed through digital gaming and that are not so neatly captured through propositions represented in multiple choice and true and false claims:
A fundamental problem in our assessment of games is that defining "educational effectiveness" is incredibly difficult. Measuring the learning outcome of a given activity is never easy, but the interactive nature of video games makes such quantification even harder. We also need to acknowledge that different kinds of computer games focus on different forms of knowledge, which are not easy to measure. Some of these knowledge forms will go largely unnoticed if we rely on, for example, simple multiple choice tests. (Egenfeldt-Nielsen, Smith, \& Tosca, 2016, p. 257)

Second, game-based learning is often assessed using in-game data logs that track students' behaviours as they move through game environments, producing a set of gameplay data. Data collected might include performance metrics such as the content accessed, time to complete tasks, and the number of "mistakes" and corrections made (Loh, Sheng, \& Ifenthaler, 2015). Yet, when digital games are used in classroom contexts, analyses of student learning that focus exclusively on built-in assessment systems can position games as though they operate in isolation from a larger learning context that includes if, how and in what ways the classroom teachers supports student learning through digital gameplay (Hébert \& Jenson, 2017) and how specifically the game is taken up in the classroom. Relying on in-game data to assess student learning can also exclude from use a wide range of commercial games from formal educational environments, "overlook[ing] the wider set of outcomes that a more diverse range of games and game-based work in schools might strive to achieve, and reflect[ing] a limited conception of the relationships between games, learning and curriculum" (Rowan \& Beavis, 2017, p. 171). The absence of built-in assessments does require a reimagining of the role of the game-based learning environment, to the extent that as Young et al. (2012) have argued "current methodologies must extend beyond their current parameters to account for the individualized nature of gameplay, acknowledging the impossibility of the same game being played exactly the same way twice and establishing that gameplay may need to be investigated as situated learning" (p. 62). But variations in how the game is used in the classroom, including the selection of activities and assessments to support learning, does create challenges for researchers in evaluating learning in these varied contexts.

To respond to a rather pressing need to produce empirical research on using digital games to support learning in K-12 classrooms, alongside the need to re-imagine assessment tools for documenting student learning that take into account the role of pedagogy and the learning environment more broadly, this article explores what students learned through playing a physical and human geography game-Sprite's Quest-and how that learning was assessed through measures that attempted to account for differences in learning environments. Sprite's Quest is platformer game, designed to teach grade 7 and 
8 students about physical and human geography concepts. Next, we discuss the game in more detail, the participants in the study, how we attempted to measure learning through student questionnaires, and conclude with a discussion of what students learned.

\section{Setting Up Learning through Sprite's Quest}

\subsection{The Game}

The games used for this study were Sprite's Quest: The Lost Feathers and Sprite's Quest Seedling Saga, two 2D platform game designed by Centre franco-ontarien de ressources pédagogiques for Ontario's Ministry of Education. The games were selected by the funding partner, the Council for Ontario Directors of Education, who was interested in better understanding how the games might be used to support student learning in the classroom. The games can be downloaded on tablets through the Apple App Store ${ }^{1}$ and Google Play Store. ${ }^{2}$ They can also be accessed online, though only by request through a school board's technology consultant, who uploads the game onto the board-based site. The games are each accompanied by a student activity guide and a teacher guide, available only through the online version of the game.

In Sprite's Quest, the game's protagonist, Sprite, is a water droplet who journeys through six physical regions-The Himalayas, Japan, Indonesia, The Nile, Iceland and Costa Rica in The Lost Feathers and Hawaii, Brazil, New York City, Egypt, Amsterdam, and China in Seedling Saga. The Lost Feathers aligns with the grade 7 Ontario geography curriculum and Seedling Saga, with the grade 8 curriculum. Through game play, students encounter the physical and human geography concepts of place, liveability and sustainability, while learning, more specifically, about transportation, waste management, population growth, and tourism, as well as processes such as erosion and the water cycle.

Game content, as it connects to geography, appears in five forms. First, information is relayed to students through facts that appear in text bubbles-both as players enter levels of the game (see Figure 1) and during gameplay (see Figure 2). Second, players are given an initial multiple choice question, requiring map reading and the interpretation of charts and graphs, as they enter a new region of the game (see Figure 3 ). Third, the environment of and processes within a region are highlighted through the background and foreground of the game as Sprite jumps atop shipping containers, for example, that serve as evidence of transportation in the region, or avoids water droplets dripping from leaves, that provide evidence of the operations of the water cycle (see Figure 4). Fourth, the water cycle is demonstrated through Sprite's metamorphoses of form, that varies de-

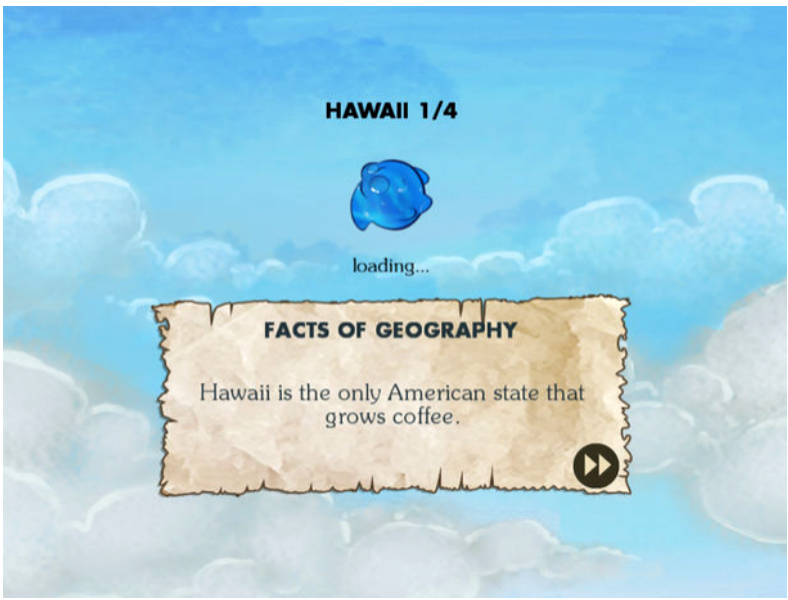

Figure 1. Fact bubbles that appear as players enter a level. ${ }^{3}$

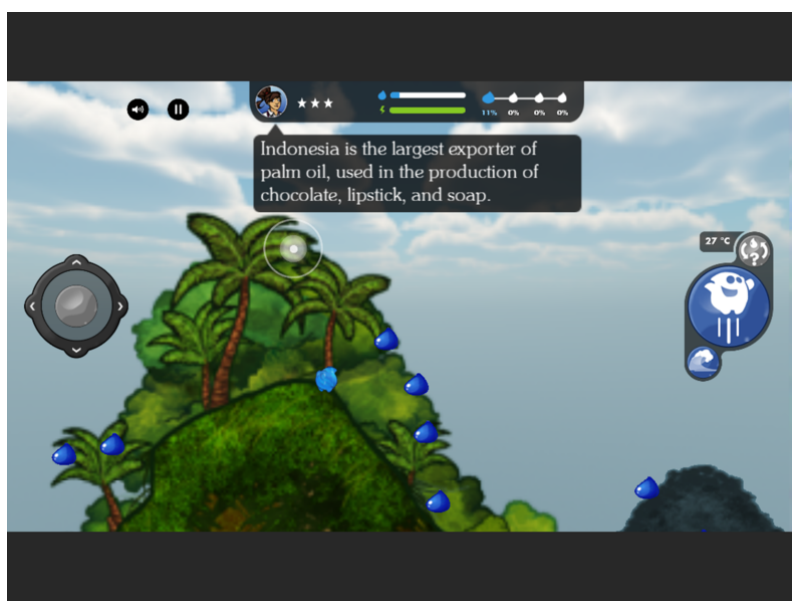

Figure 2. Fact bubbles that appear during gameplay.

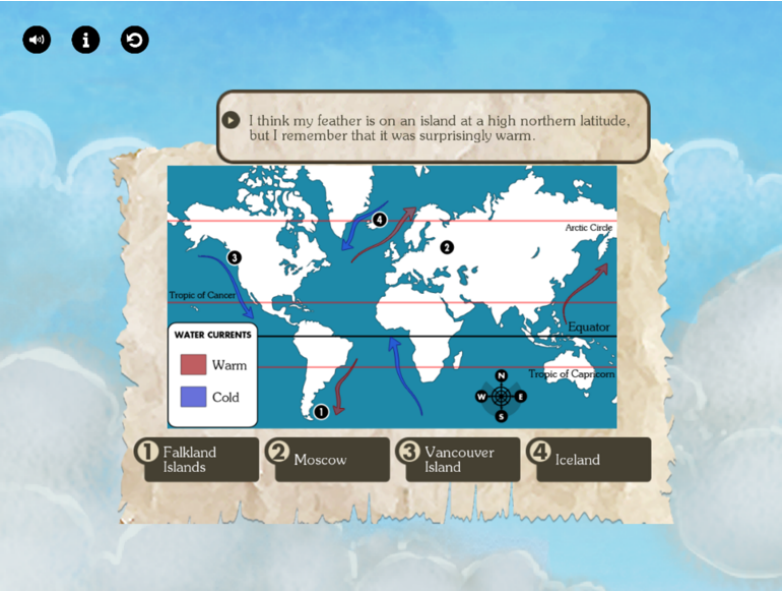

Figure 3. Questions to complete for entry into region.

pending on the elevation and temperature of the region; the water droplet becomes a vapor cloud at high altitudes or a piece of ice in colder climates (see Figure 5).

\footnotetext{
${ }^{1}$ https://itunes.apple.com/ca/app/sprites-quest-the-lost-feathers/id972933557?mt=8 (The Lost Feathers);

https://itunes.apple.com/ca/app/sprites-quest-seedling-saga/id973216081?mt=8 (Seedling Saga).

2 https://play.google.com/store/apps/details?id=com.cforp.ELOGR7\&hl=en (The Lost Feathers);

https://play.google.com/store/apps/details?id=com.cforp.ELOGR8\&hl=en (Seedling Saga).

3 C Centre franco-ontarien de ressources pédagogiques, 2016. Reproduced with the permission of the CFORP.
} 
And fifth, the game contains a water vault that, when visited, can inform players about how much water is required in the production of various objects, such as a cup of milk, coffee, or tea (see Figure 6).

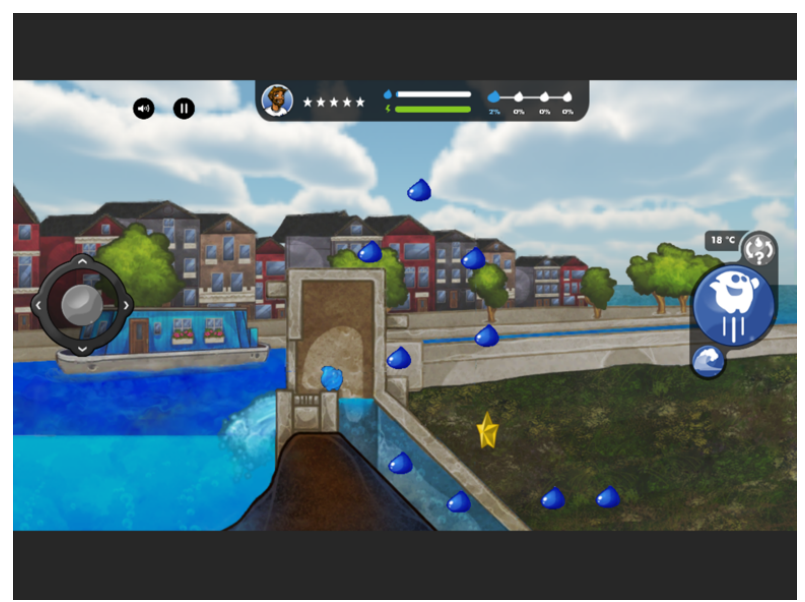

Figure 4. Players learn about geography through the background and foreground of the game.

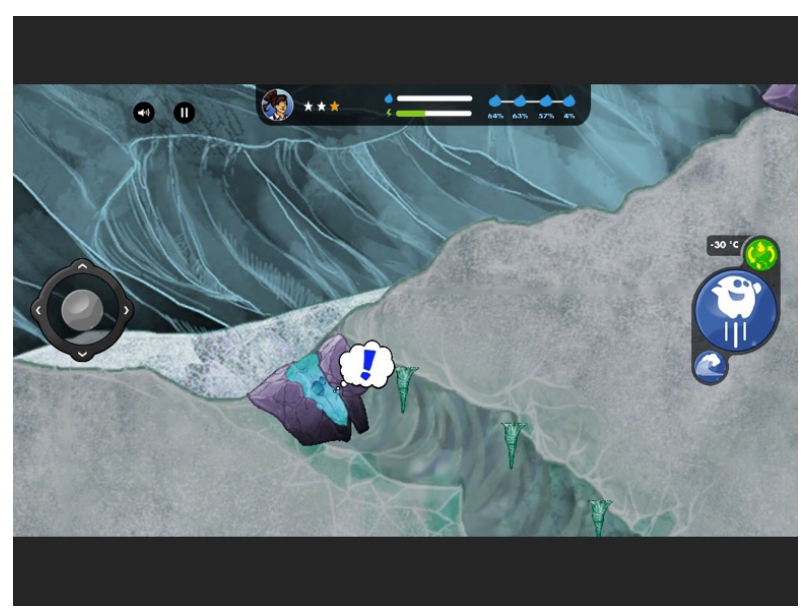

Figure 5. Sprite changes form from a water droplet to a piece of ice.

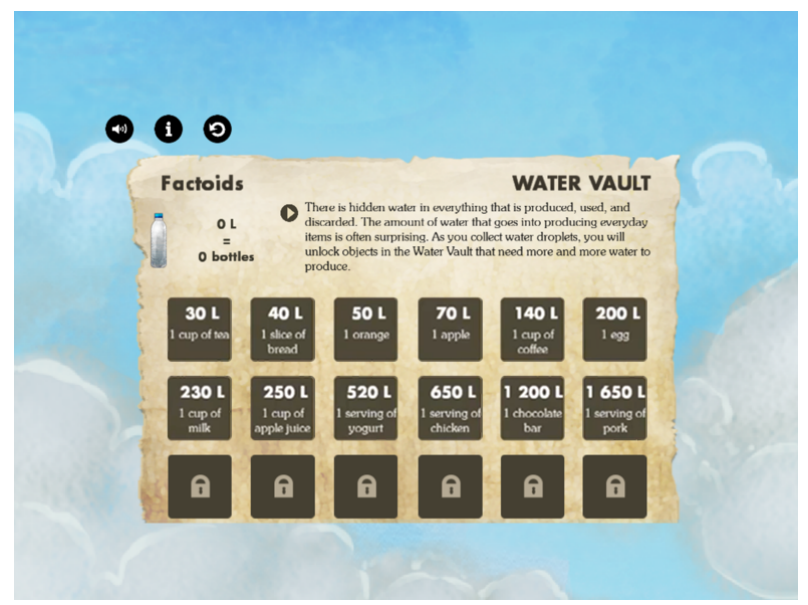

Figure 6. Water vault.

\subsection{Open-Ended Learning in Sprite's Quest}

It is important to note that the game did not contain a tracking system. Assessments of student learning were not built into the game and the game mechanics, in the sense that a player might respond to a question that pops up during or after play and be evaluated on this response within the electronic game-based learning system. While students complete multiple choice questions for one aspect of the game content-to gain entry into a levelno data is collected within the game about the whether or not questions are answered correctly. Other assessment metrics, such as level completion time or number of items collected in the water vault, are also not gathered through gameplay. To support student learning using Sprite's Quest, then, the teacher is required to either design assessments that can be used alongside the game and/or use the student guide.

The student guide (see Figure 7), targeted at each game, includes three During Game Play activities, one set of discussion questions per level, and a culminating activity for each region. All are rather open-ended. For the gameplay activities, the first, What's Where/There, Why There, Why Care, requires the identification of objects (e.g., animals, landforms, signs) in levels and an accompanying explanation of their significance to the region (see Figure 8). For the second activity in The Lost Feathers, labeled Natural Processes, students are provided a set of diagrams which are to be interpreted for the geographic processes they explain (see Figure 9). In Seedling Saga, the Human Systems activity asks students to identify elements of liveability within a region (see Figure 10). And in the third activity, Through the Eyes of the Artists, students compare an image in the game to a similar image online and compose a written critical response about similarities and differences (see Figure 11). Discussion questions, the least open-ended of the assessment tools, vary by level, but focus on a critical analysis of issues concerning a specific region. For example, for level one of Egypt, students are asked about the benefits of living along a river bank, what type of decisions would need to be made around infrastructure to build a city along a river, and about preserving historic sites such as pyramids. Finally, culminating activities consist of larger tasks such as writing a persuasive paragraph about a spe-

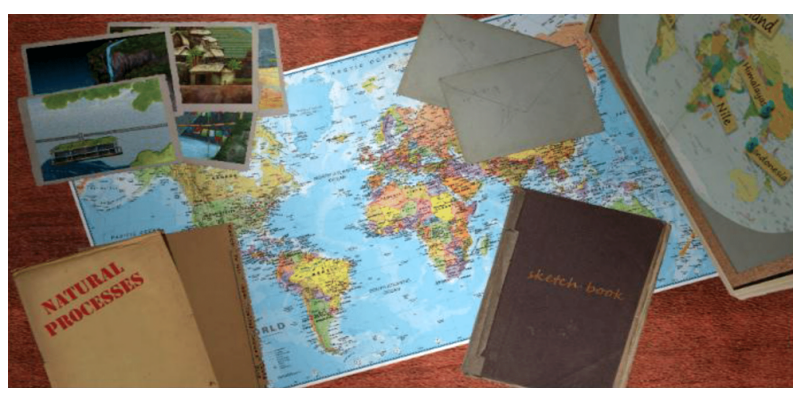

Figure 7. Main page of digital student guide. 
cific environmental issue considering multiple perspectives, or critically analyzing maps and graphs as they relate to a particular area.

In addition to including open-ended activities, the game leaves much to teacher interpretation, including how activities might be evaluated and how the game might be used in the classroom. While the teacher guide does contain learning goals, success criteria, and expectations that might be distributed to students along with possible student responses, nothing is included that might standardize correct responses, such as rubrics. Suggestions on how to incorporate the game into the curriculum are outlined, in the teacher guide, as follows:

Teachers are encouraged to use their professional judgement on how best to incorporate the game and supporting resources into their program. How it is used depends on the available classroom time and access to technology. An extensive use of the game might require three 40-minute periods per location-

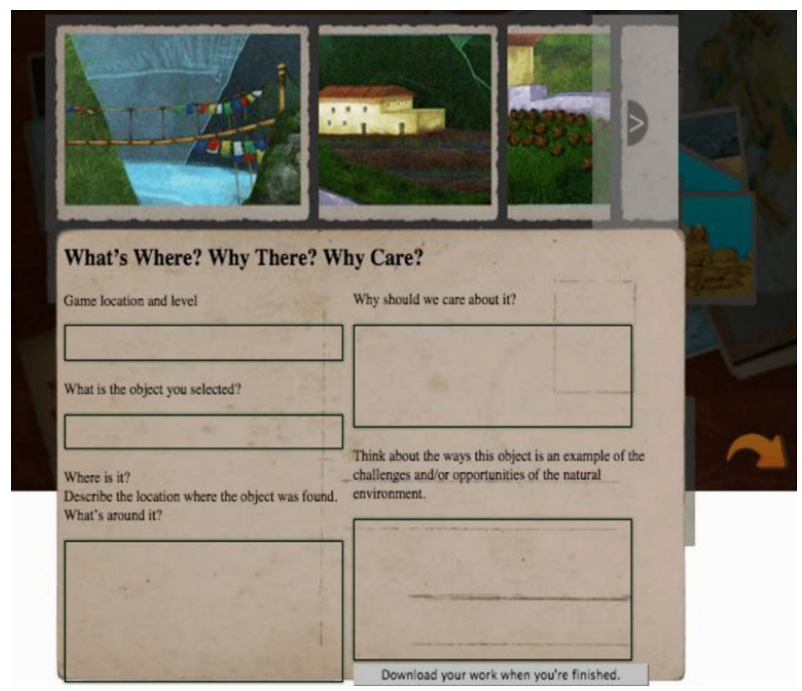

Figure 8. What's where/there? Why there? Why care? activity.

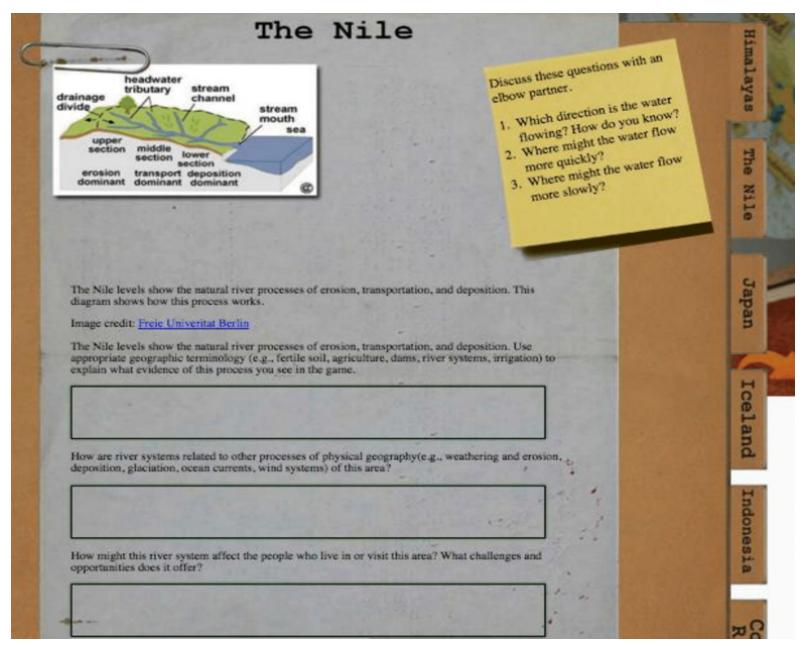

Figure 9. Natural processes activity. two to play the levels and do the During Game Play activities. In addition, the culminating activity will take at least one additional period. This, however, can be streamlined according to your available classroom time. For example, you can have your students play through all four levels for a location in a single period, and then complete one selected culminating task for that location's set of levels. You may also wish to look for opportunities for cross-curricular integration, such as incorporating the perspectives activity into your language program or the climate graphs into your data management mathematics strand. (Centre francoontarien de ressources pédagogiques, 2016, p. 2)

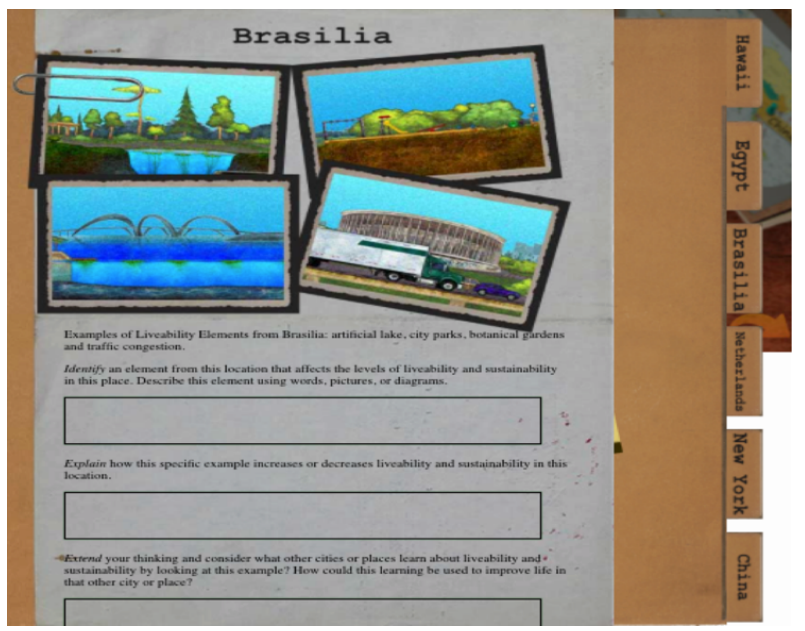

Figure 10. Human systems activity.

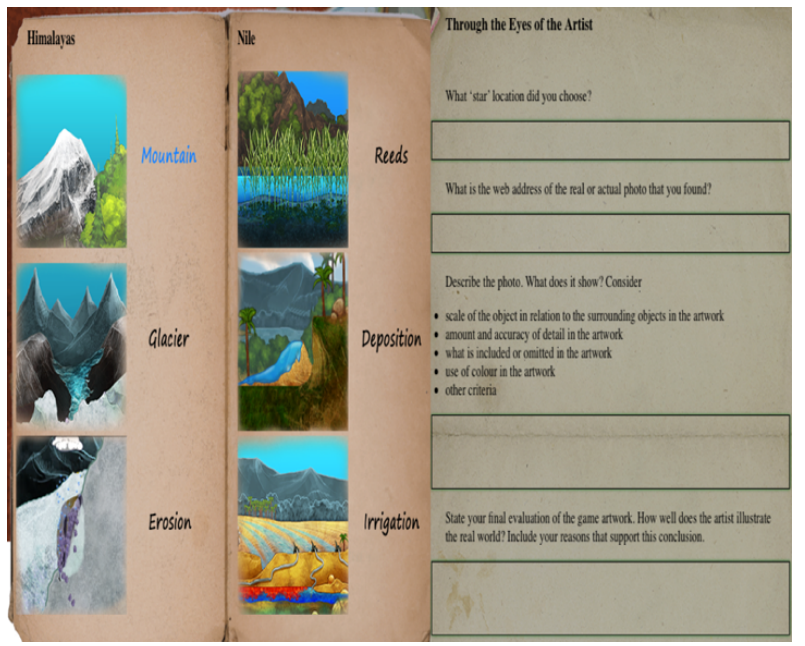

Figure 11. Through the eyes of the artist activity.

\section{Studying the Use of Sprite's Quest in the Classroom}

The purpose of this study was twofold. First, we wanted to examine the impact of a professional development session on fostering the creation of a classroom environment conducive to game-based learning. While professional development is not the focus of this particular 
article, and the results of this aspect of the research have been discussed elsewhere (Hébert \& Jenson, 2017), this aim is important to note as it relates to the framing of the study. ${ }^{4}$ Relatedly, we wanted to evaluate, empirically, student learning through the use of this particular game in the classroom. The open-ended nature of the game, and teachers' autonomy with regard to how the game would be played is significant as it pertains to how we, as researchers, could evaluate learning. The research question that framed this segment of the study was: what did students learn about physical and human geography through the Sprite's Quest unit?

\subsection{Participants}

Participants consisted of grade $6,7,8$, and 9 students, ${ }^{5}$ across 9 school boards and in 24 different schools -13 suburban, 6 urban and 5 rural. 795 students and their 32 teachers participated in the study. Classes were quite varied in grade make-up, with 22 single grade classes (14 grade 7,7 grade 8 , and 1 grade 9 ) and 10 split classes (1 grade $6 / 7 / 9,1$ grade $6 / 7$ and 8 grade $7 / 8$ ).

\subsection{Professional Development and Planning the Sprite's Quest Unit}

Teachers were invited to attend a two-day workshop ${ }^{6}$ on how to create a classroom environment conducive to game-based learning, specifically, around Sprite's Quest. At the workshop, teachers were given time to play the game and become familiar with the teacher and student activity guides. As noted, slightly less than half of the teachers who participated in the study had students in their class from multiple grades, and so, could choose to use either one or both of (the) game(s) for the entire class, to divide the class by grade and use The Lost Feathers with grade 6/7 students and Seedling Saga with grade 8 students, or to introduce both games to the class and allow individual students the chance to decide which game to play. For planning, teachers were placed in small groups to create a unit around Sprite's Quest and to brainstorm possible assessments, provided with the flexibility to build off of the activities provided in the student activity guides and/or to design their own activities and assessments. This flexibility was important for: 1) maintaining teacher autonomy over the content of their curriculum and for using the game in a manner that would best support student learning; and 2) opening up possibilities to use the game to support cross-curricular learning, such as in support of the language arts or mathematics curriculum, in addition to geography. At the end of the workshop, teachers presented unit plans and assessment ideas to the group. Teachers were also asked to create the individual unit plans they would use in their class- room and submit them electronically to the researchers prior to the start of the gameplay unit.

\subsection{Data Collection}

This study took a quantitative approach to data collection. Data consisted of pre (see Appendix A) and post (see Appendix B), pencil and paper questionnaires. The pre questionnaire was administered to students prior to the first lesson and a post questionnaire given the end of the unit. Given that researchers were not present for the duration of the game-based unit, questionnaires were administered by classroom teachers. Researchers picked up the pre questionnaires during site visits to individual classrooms, while post questionnaires were returned by the teachers in a pre-paid express envelope. Due to the different means of questionnaire collection (e.g., post questionnaires had to be mailed) and general, expected attrition, fewer post questionnaires were returned than pre questionnaires; 795 pre questionnaires were received compared to 540 post questionnaires. Questionnaires focused on student media use and learning through the game. The questionnaires will be discussed in more detail below as they created some challenges with respect to evaluating student learning with the game.

\section{Sprite's Quest in The Classroom: Activities and Assessments}

Given the open-endedness of the Sprite's Quest learning environment, the autonomy granted to teachers around how the game was taken up in their classroom, and the various needs of classes, including split grade classes, the game and its unit varied greatly. For example, the length of time spent on the game differed by teacher and ranged from three periods (of approximately $45 \mathrm{~min}$ utes) on the lower end of the spectrum to sixteen for classes that used the game more comprehensively. The activities used to support learning also differed by class. Most teachers did incorporate one or more of the activities from the student guide into their unit, printing or using the activities online, or modifying and building off of them. Teachers also decided to assess learning through the game in a wide variety of ways. Many offered formative assessments during the unit, providing feedback on discussion questions or play accountability sheets, for example, and evaluated students summatively on one final assignment-completing one of the culimating activities in the activity guide, being the most common form of summative assessment. Others provided one grade for students based on all of the work submitted.

Overall, what specifically teachers did over the course of the Sprite's Quest unit was difficult to track.

\footnotetext{
${ }^{4}$ The control group for the study contained teachers who did not receive professional development.

${ }^{5}$ In Ontario, students in these grades would typically be 11 to 15 years of age.

${ }^{6}$ As a goal of the study was to examine the impact of the professional development session on teachers' classroom practice, additional teachers were invited to participate in the study who were not provided with PD (see Hébert \& Jenson, 2017, for discussion of the impact of PD on teaching). In total, 28 teachers received PD and six did not.
} 
Given that researchers were not present for the duration of the unit, we relied upon teachers' blog posts, accounts of their activities and assessments during interviews, and submission of activities and assessments. However, teachers blogged less frequently than we had hoped, likely owing to time constraints of planning and implementing a new unit. Also, as is the nature of translating plans into practice and responding to the needs of students, many teachers deviated from the initial unit plan submitted. Together, this resulted in challenges with creating a thorough and detailed account of the Sprite's Quest unit as it unfolded in individual classroom spaces.

\section{Results: Student Learning}

\subsection{Students' Device and Media Use}

For videogames in particular, the majority of the students who participated in the study played videogames with 557 (70\%) indicating that they have access to and regularly use a game console and 237 (30\%) reporting that they did not have access to and regularly use one. Using a 5-point Likert scale, students were asked about their frequency of play, with 0 indicating that students "never" play games, 1 "1-2 times per month", 2 "1-3 times per week", 3 "5-6 times per week" and 4 "5-9 hours per week". With scores averaged, the most frequent play times were reported for mobile or tablet games (2.62 out of 4), with only slightly lower frequency reported for handheld device games (2.16 out of 4), console videogames (2 out of 4 ), massively multiplayer online games (1.57 out of 4 ) and computer videogames (1.57 out of 4$)$.

\subsection{Student Learning: Multiple Choice Questionnaire Questions}

Student learning was assessed through multiple choice questions, focusing on physical geography terminology. Questionnaires contained four multiple choice questions about weathering, erosion, tectonic plates, and phases of the water cycle, to which all students were asked to respond. These questions were developed by researchers based on concepts that appeared throughout both The Lost Feathers and Seedling Saga. The same questions were included on both the pre and post questionnaires. To ensure that change scores were captured in analysis, data included questionnaires where students had completed both the pre and post test. For this reason, the sample size was smaller than the initial prequestionnaire ( $n=540$ ). Multiple choice change scores were calculated by subtracting pre questionnaire multiple choice scores from post questionnaire multiple choice scores (MCchange $=$ PosttestMC-PretestMC). Students had a mean score of 2.32 out of $4(S D=1.16)$ on the pre test and $2.56(S D=1.18$ ) out of 4 on the post test. Multiple choice scores increased an average of 0.24 points $(S D=1.17$ ) between the pre and post test. A paired t-test indicated a statistically significant difference between pre test and post test multiple choice scores, $t(539)=-4.80, p<.001$. Previous experience playing videogames did not have any bearing on students' scores.

\subsection{Student Learning: Short Answer: Quantitative Analysis}

For the short answer section of the questionnaire, the questions were divided by game, and students asked to respond to two or three of five questions for The Lost Feathers and/or for Seedling Saga. On the pre questionnaire, questions were taken directly from the student activity guides and mainly focused on table, map and graph reading, with the exception of one general question about plate tectonics from the student activity guide and four general questions that asked students to define liveability, sustainability and place and identify the "types of things" geographers might look to "in order to understand liveability in a particular area". The post questionnaire differed slightly in structure. First, the post questionnaire was longer, and students were asked to respond to three or four of seven short answer questions. Second, in addition to table, map, graph reading and short answer questions taken directly from the student guide, researchers included a general question for each game that asked students to select a specific level of the game that they played, identify objects from that region and explain their significance. This question allowed for students to capture their learning more specifically by writing about a particular location that they played.

Given the open-endedness of the activities and assessments provided for the game and variety of ways that teachers could take up the game in class according to their curricular and grade-based needs, the questionnaire did not include directions as to what section of the short answer questions should complete. As a result, some classes completed the questionnaire in its entirety, regardless of game played, while others filled out the sections of the questionnaire that corresponded with playing either The Lost Feathers or Seedling Saga in class. Questions included in analysis corresponded with the game students played in class and the corresponding questions completed on the questionnaire. Additionally, while students were asked to complete two or three short answer questions in the pre questionnaire and three to four questions in the post questionnaire, some students completed more. In such cases, all questions were evaluated and the top two and top three scores were included for analysis from the pre and post questionnaires respectively, based on the game(s) the students played in class.

As the number of possible answers varied from pre to post test, individual scores were converted into percentages to obtain mean scores and to evaluate change scores. On the pre test, students had a mean score percentage of $39 \%(S D=1.63)$ compared to a post test mean 
percentage score of $44 \%$ ( $S D=2.42)$, with a change score of $5.12 \%(S D=25.3)$. A paired t-test indicated that the difference between students' pre test short answer scores and post test short answer scores were statistically significant, $t(539)=-4.71, p<.001$.

We were interested in determining whether the questions that offered students the opportunity to select an object from a location played, to identify it and explain the object's significance were related to both higher change scores and higher post test scores. In other words, we wanted to know if providing students more openness with respect to demonstrating their learning resulted in higher scores than more closed questions that narrowed the learning that could be expressed. In comparing scores, performance on the questions where students had to identify three objects/features within a particular geographic region was related to both change scores and total post test scores, where better performance on the geographic region object question predicted more improvements between the pre and post test $(r=0.25$, $p<.001)$ and higher scores on the overall post test $(r=.53, p<.001)$. It should be noted that these results are not necessarily the most reliable measure. If students did well on one of these questions, it's likely that it was selected as one of their best 3 answers, and therefore contributed to their overall post test score. Thus, the shared variance here can lead to some misleading conclusions regarding the importance of performance on this question as it relates to overall performance.

\section{Discussion}

This study demonstrated that even under radically different conditions, with a diverse population of students and teachers, and variation in pedagogy, this particular digital game supported student learning. On both multiple choice and short answer questions, students overall demonstrated a significant improvement having played the game and completed the curriculum unit designed by their teachers around the game. That conditions varied widely between classes did not seem to effect the overall gains, nor did differences between students. Whether or not students had previously spent time playing games did not correlate with their overall scores, and we did not control for those students who were English Language Learners or had learning disabilities. This study, then, goes some way in demonstrating that learning can be supported through game-based play.

We did encounter a number of challenges with this study that raise questions about how to assess student learning using digital games, in K-12 classrooms, where learning is often messy and complex. First, prior, future, and cross-curricular learning are significant considerations in understanding how students make connections between the game and the curriculum. While, in our study, teachers designed a unit around the use of Sprite's Quest in the classroom, many connected the game to larger class discussions already underway-as part of the geography curriculum - about pollution, waste management, designing communities, and travel and tourism. Teachers also highlighted learning in mathematics while reading charts and graphs, and in history, in reading images in the game and discussing authorship and context. If we are to conceptualize digital games as one form of media used to support student learning within an expansive, multi-disciplinary curriculum, how students make meaning drawing from a wide variety of curricular resources needs to be taken into account. This makes isolating learning through a particular medium, such as a digital game, rather challenging. To wholly capture how the digital game figures into student learning, researchers would likely need to be present for the duration of the school year, a feat not feasible in studies with a large number of participants.

While standardized assessment models are the norm in game-based studies, either administered to players in the form of tests pre and post play or through in-game, or stealth systems (All, Nunez Castellar, \& Van Looy, 2014), they fail to adequately measure learning that can be expressed outside of the literal box and take into account immense differences between learning contexts. If game-based learning environments constitute not only the game but also the classroom in which the game is used, assessments of learning need to be open enough to account for these differences and to allow space for the messiness and uncertainty of both teaching and learning in digital environments. In these contexts, digitalgames might not be conceptualized as stand-alone interventions but as part of a broader learning context, where games are used in conjunction with other media and where the role of the teacher is positioned as a pivotal element of the learning process.

\section{Conclusion}

While we were not able to report on the study in its entirety, this article examines the impact of a curriculum unit focused on a digital game in 32 diverse geography classrooms. Even given the complexities of negotiating research in so many classrooms and under such diverse conditions, this study shows a measurable gain in learning and understanding for students who participated. Indeed, what we think is worth highlighting here is that even as students might have played the game from anywhere between one hour to up to tweleve hours, and that 32 teachers decided to approach the integration of the game in a different way (using worksheets, the student guide, the teacher's guide, and/or no use of guides), the data showed a measurable gain for the majority of the study's participants. Further, and related to previous literature on games and learning (All et al., 2014; Buch \& Egenfeldt-Nielsen, 2007), we have reported on the messiness of trying to "measure" gains from gameplay when it is difficult to isolate that from the other learning opportunities that are available in a classroom environment. 
Here, we have attempted to take up the challenge set by Young et al. (2012), who argued that we need to produce better research on game-based learning. At the conclusion of their article, they draw a metaphorical picture of what research is needed in this area, referencing Super Mario Brothers and its heroes Mario and Luigi, who embark on a quest to save the princess, writing: "let us prepare our blue overalls and plungers as we embark on the next journey through the warp pipe to find the right princess in the right castle...eventually producing the highest score: engaging and effective student learning" (pp. 84-85). While we did not fully achieve that aim, we certainly can say with some confidence that learning can be supported through digital gameplay, even in very different classroom environments. However, how best to measure that, and how to better document the messiness that accompanies school-based studies remains a significant challenge.

\section{Acknowledgments}

We would like to acknowledge the Council for Ontario Directors of Education for funding the project, and the teachers and students for participating.

\section{Conflict of Interests}

The authors declare no conflict of interests.

\section{References}

All, A., Nunez Castellar, E. P., \& Van Looy, J. (2014). Measuring effectiveness in digital game-based learning: A methodological review. International Journal of Serious Games, 1(2), 3-20.

Annetta, L. (2008). Video games in education: Why they should be used and how they are being used. Theory Into Practice, 47(3), 229-239. doi:10.1080/ 00405840802153940

Brysch, C. P., Huynh, N. T., \& Scholz, M. (2012). Evaluating educational computer games in geography: What is the relationship to curriculum requirements? Journal of Geography, 111(3), 102-112. doi:10.1080/ 00221341.2011 .609998

Buch, T., \& Egenfeldt-Nielsen, S. (2007). The learning effect of "Global Conflicts: Palestine". Medi@Terra Conference, 2006. Retrieved from http://citeseerx.ist. psu.edu/viewdoc/download?doi=10.1.1.135.7582\& rep=rep $1 \&$ type $=p d f$

Centre franco-ontarien de ressources pédagogiques. (2016). Teacher resources: The lost feathers. Ottawa.

Cheung, K. K. F., Jong, M. S. Y., Lee, F. L., Lee, J., Luk, E., Shang, J., \& Wong, M. (2008). FARMTASIA: An online game-based learning environment based on the VISOLE pedagogy. Virtual Reality, 12(1), 17-25.

da Silva, C. N. (2015). Interactive digital games for geography teaching and understanding geographical space. Creative Education, 6(5), 692-700.
Dittmer, J. (2010). Immersive virtual worlds in universitylevel human geography courses. International Research in Geographical and Environmental Education, 19(2), 139-154. doi:10.1080/10382046.2010. 482222

Dourda, K., Bratitsis, T., Griva, E., \& Papadopoulou, P. (2014). Content and language integrated learning through an online game in primary school: A case study. Electronic Journal of E-Learning, 12(3), 243-258.

Egenfeldt-Nielsen, S., Smith, J. H., \& Tosca, S. P. (2016). Understanding video games: The essential information (3rd ed.). New York, NY: Routledge.

Gee, J. P. (2005). Are videogames good for learning? Spectrum, 32, 25-32. Retrieved from http://cmslive. curriculum.edu.au/leader/default.asp?id=16866\& issuel $\mathrm{D}=10696$

Hébert, C., \& Jenson, J. (2017). Digital game-based pedagogy: Exploring teaching strategies for classroom teachers in the use of video games in $\mathrm{K}-12$ classrooms. Paper presented at the European Conference on Games Based Learning, Graz, Austria.

Jenson, J., de Castell, S., Thumlert, K., \& Muehrer, R. (2016). Deep assessment: An exploratory study of game-based, multimodal learning in Epidemic. Digital Culture and Education, 8(March), 21-40.

Kirriemuir, J., \& Mcfarlane, A. (2007). Literature review in games and learning. NESTA Futurelab. Retrieved from https://telearn.archives-ouvertes.fr/hal-00190 453/document

Linderoth, J. (2012). Why gamers don't learn more: An ecological approach to games as learning environments. Journal of Gaming and Virtual Worlds, 4(1), 45-62.

Loh, C. S., Sheng, Y., \& Ifenthaler, D. (2015). Serious games analytics: Theoretical framework. In C. S. Loh, Y. Sheng, \& D. Ifenthaler (Eds.), Serious games analytics: Methodologies for performance measurement, assessment, and improvement (pp. 3-29). Cham: Springer.

Mitchell, A., \& Savill-Smith, C. (2004). The use of computer and video games for learning: A review of the literature. Retrieved from http://health.utah.gov/ eol/utc/articles/use_of_games_for_learning.pdf

Prensky, M. (2006). Don't bother me mom. I'm learning! St Paul, MN: Paragon House.

Rowan, L., \& Beavis, C. (2017). Serious outcomes from serious play. In C. Beavis, M. Dezuanni, \& J. O'Mara (Eds.), Serious play: Literacy, learning and digital games (pp. 170-185). New York, NY: Routledge.

Shaffer, D. W., Squire, K. D., Halverson, R., \& Gee, J. P. (2005). Video games and the future of learning. Phi Delta Kappan, 87(2), 105-111. doi:10.1002/ piq. 20020

Squire, K., \& Jenkins, H. (2003). Harnessing the power of games in education. Insight, 3, 5-33.

Tüzün, H., Yilmaz-Soylu, M., Karakuş, T., Inal, Y., \& Kizilkaya, G. (2009). The effects of computer games 
on primary school students' achievement and motivation in geography learning. Computers and Education, 52(1), 68-77. doi:10.1016/j.compedu. 2008.06.008

Virvou, M., Katsionis, G., \& Manos, K. (2005). Combining software games with education: Evaluation of its educational effectiveness. Educational Technol- ogy and Society, 8(2), 54-65. doi:10.1016/j.corsci. 2007.02.007

Young, M. F., Slota, S., Cutter, A. B., Jalette, G., Mullin, G., Lai, B., ... Yukhymenko, M. (2012). Our princess is in another castle: A review of trends in serious gaming for education. Review of Educational Research, 82(1), 61-89. doi:10.3102/0034654312436980

\section{About the Authors}

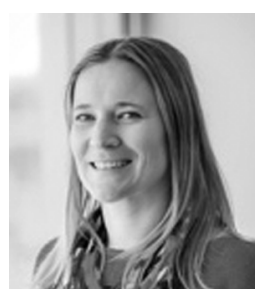

Cristyne Hébert is a postdoctoral researcher at the Institute for Research on Digital Learning at York University. Her research focuses on assessment and evaluation, new media and technologies, and curriculum in teacher education and K-12 education in Canada and the United States.

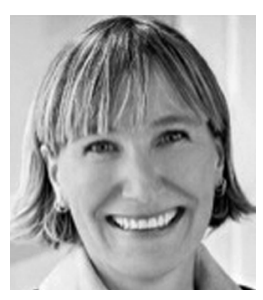

Jennifer Jenson is Director of the Institute for Research on Digital Learning and Professor of Pedagogy and Technology in the Faculty of Education at York University, Canada. She has published on games and learning, gender, games and technology and technology policy and policy practices in K-12 education in Canada.

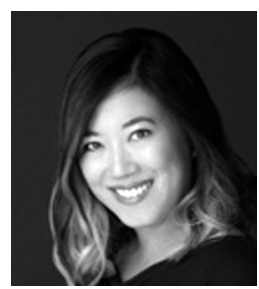

Katrina Fong (PhD) is a doctoral graduate from York University in the area of Social and Personality Psychology. Katrina's primary research focus is on understanding the relationships between media and individuals, particularly with regard to video games and avatars. Her previous work has included journal publications and book chapters in the area of psychology, narrative, media, identity, and person perception. 


\section{COGITATIO}

\section{Appendix A. Pre-Questionnaire Questions}

\section{A1. Physical Geography Terminology}

40. What does "weathering" mean?
a) a distinct layer of soil encountered in the vertical section
b) work performed according to a binding contract between two parties
c) a flowing mixture of water and debris that forms on the slopes of a volcano
d) the breaking down of rocks, soil, and minerals through contact with the earth's atmosphere
e) I don't know

41. What does "erosion" mean?
a) rain that becomes more acidic than normal
b) the process by which the surface of the earth is worn away
c) when water is turned into gas
d) a fracture of the earth's crust
e) I don't know

42. What are "tectonic plates"?
a) plates that glide over the Earth's mantle
b) a permanently frozen layer of rocks
c) a line of bold cliffs
d) an area of diminished precipitation on the downside of a mountain
e) I don't know

43. What are the phases of the "water cycle"?
a) liquid, gas, land
b) liquid, solid, gas
c) liquid, solid, ether
d) solid, gas, bubbles
e) I don't know

A2. Other Geography Short Answers: Sprite's Quest: The Lost Feathers

Answer two or three questions in this section as best you can.

44. What do the arrows show on the diagram?

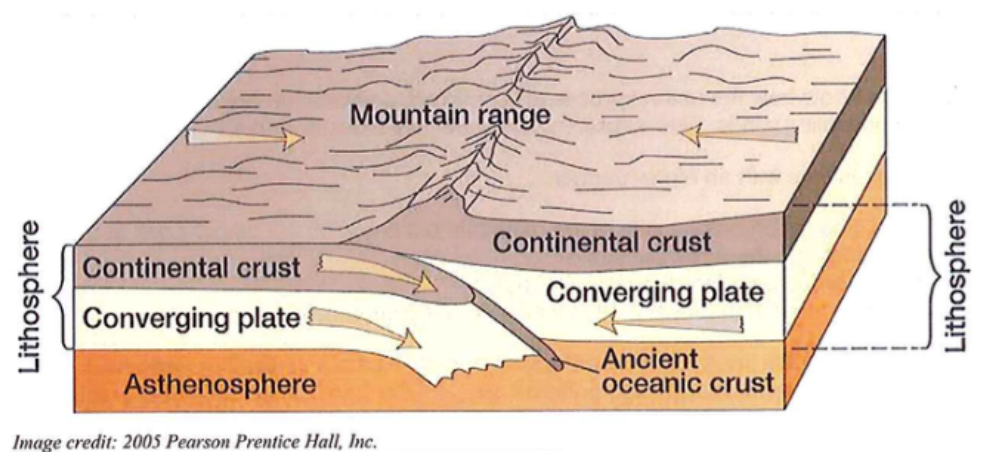




\section{COGITATIO}

45. Which direction is the water flowing and how do you know?

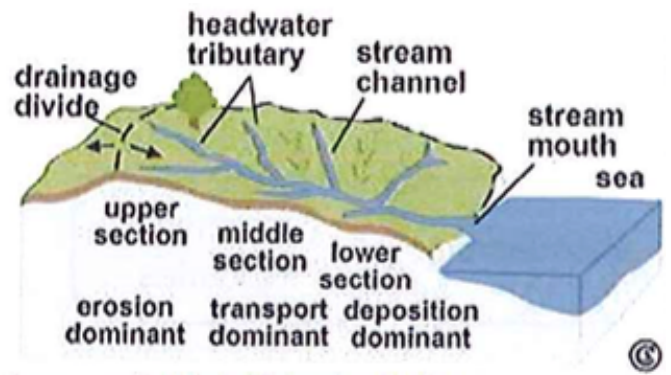

Image credit: Freie Univeritat Berlin

46. What is the disadvantage of living on the west side of the island of Sumatra? What proof can you find on the map?

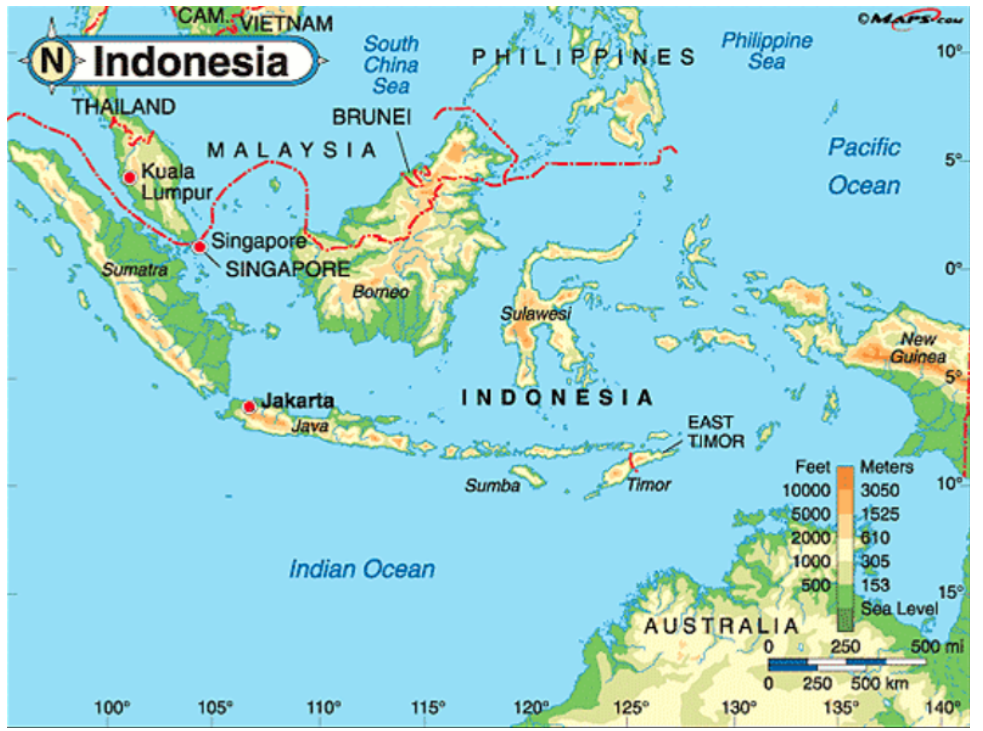

47. What information, if any, is missing from this graph?

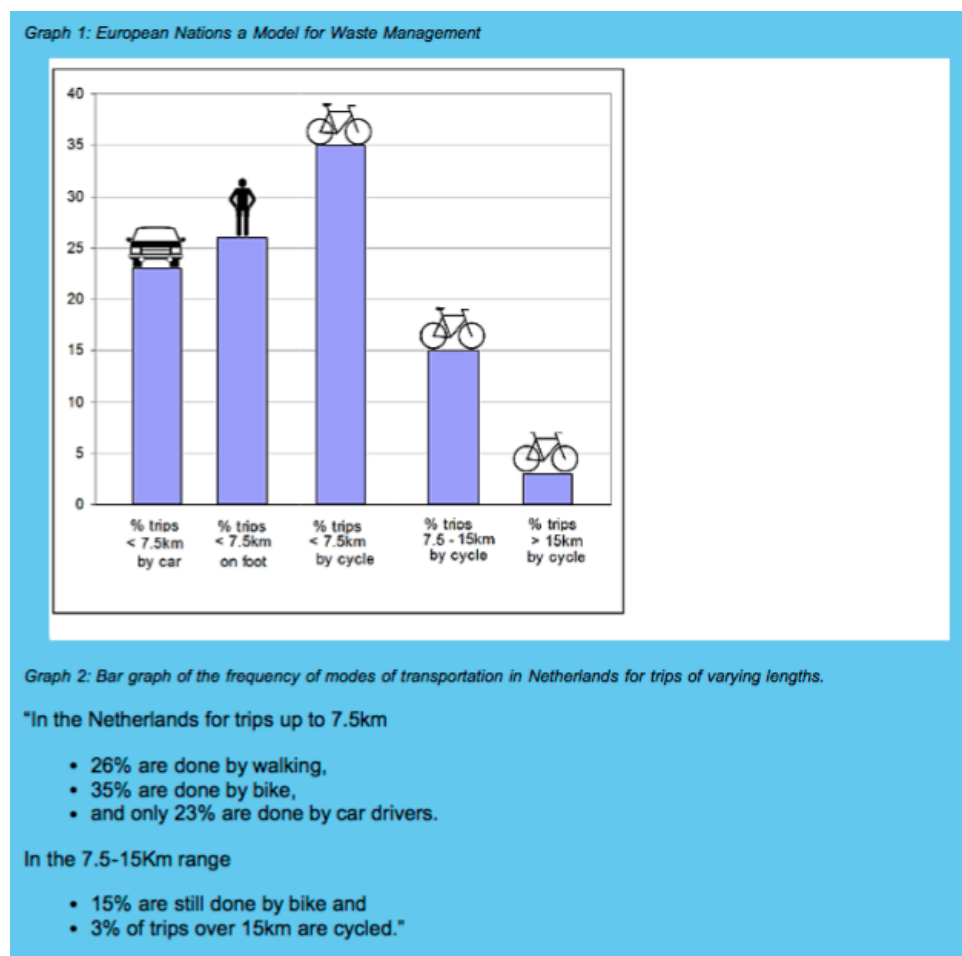


48. How could plate tectonics be used to explain the hot springs found in both Iceland and Japan?

A3. Other Geography Short Answers: Sprite's Quest: Seedling Saga

Answer two or three of these questions as best you can.

49. What does "place" refer to in geography?

50. What does "liveability" refer to in geography?

51. What types of things might geographers look at to understand liveability in a particular area?

52. What is "sustainability"?

53. Briefly describe this graph's pattern.

\section{Appendix B. Post-Questionnaire Questions}

\section{B1. Physical Geography Definitions}

11. What does "weathering" mean?

a) a distinct layer of soil encountered in the vertical section

b) work performed according to a binding contract between two parties

c) a flowing mixture of water and debris that forms on the slopes of a volcano

d) the breaking down of rocks, soil, and minerals through contact with the earth's atmosphere

12. What does "erosion" mean?
a) rain that becomes more acidic than normal
b) the process by which the surface of the earth is worn away
c) when water is turned into gas
d) a fracture of the earth's crust

13. What are "tectonic plates"?
a) plates that glide over the Earth's mantle
b) a permanently frozen layer of rocks
c) a line of bold cliffs
d) an area of diminished precipitation on the downside of a mountain

14. What are the phases of the "water cycle"?
a) liquid, gas, land
b) liquid, solid, gas
c) liquid, solid, ether
d) solid, gas, bubbles

\section{B2. Physical Geography Short Answers}

15. What does "place" mean in geography?

16. What does "liveability" mean in geography?

17. What types of things might geographers look at to understand liveability in a particular area?

18. What is "sustainability"? 


\section{COGITATIO}

\section{B3. Questions Directly Related to The Videogame}

19. What are three geographical objects someone might find in Hawaii?

a)

b)

c)

20. Choose one of the objects above and explain how and why it is important for people living in that area.

21. What are three geographical objects someone might find in New York City?
a)
b)
c)

22. Choose one of the objects above and explain how and why it is important for people living in that area.

23. What are three geographical objects someone might find in The Himalayas?
a)
b)
c)

24. Choose one of the objects above and explain how and why it is important for people living in that area.

25. What are three geographical objects someone might find in Costa Rica?
a)
b)
c)

26. Choose one of the objects above and explain how and why it is important for people living in that area.

27. What do the arrows show on the diagram?

28. Which direction is the water flowing and how do you know?

29. What issues would Hawaiians face given that they rely on imports for many of the goods they use in their daily lives, such as oil?

30. Why won't our typical local farming techniques (tractors and large fields) work in mountain ranges? Why are different crops grown in different regions?

31. What is the disadvantage of living on the west side of the island of Sumatra? What proof can you find on the map?

32. What information, if any, is missing from this graph?

This is the end of the survey.

Thank you. 